\title{
KNOW THE LEDGE WE'RE ON from Accountability to Activist Research
}

WORKSHOP: University-based researchers are involved in a wide variety of collaborations and partnerships with individuals, collectivities and organizations including - but not limited to - NGOs, community organizations, activist political movements, and local, national and transnational governments, agencies, and networks. This workshop invites debate and discussion about practices, promises, and power in research relationships. How do we work with/in shifting grounds of knowledge and certainty?

KEYNOTE SPEAKER: Professor Dian Million (American Indian Studies, University of Washington). Million's work interweaves analyses of political movements and autobiographical writing with debates among scholars, politicians, writers, artists and activists.

Friday, April 17, 2015 9:30am - 5:30pm | Room HC 2270

\section{Harbour Centre}

Simon Fraser University 515 W. Hastings St. Unceded Coast Salish Territories/Vancouver

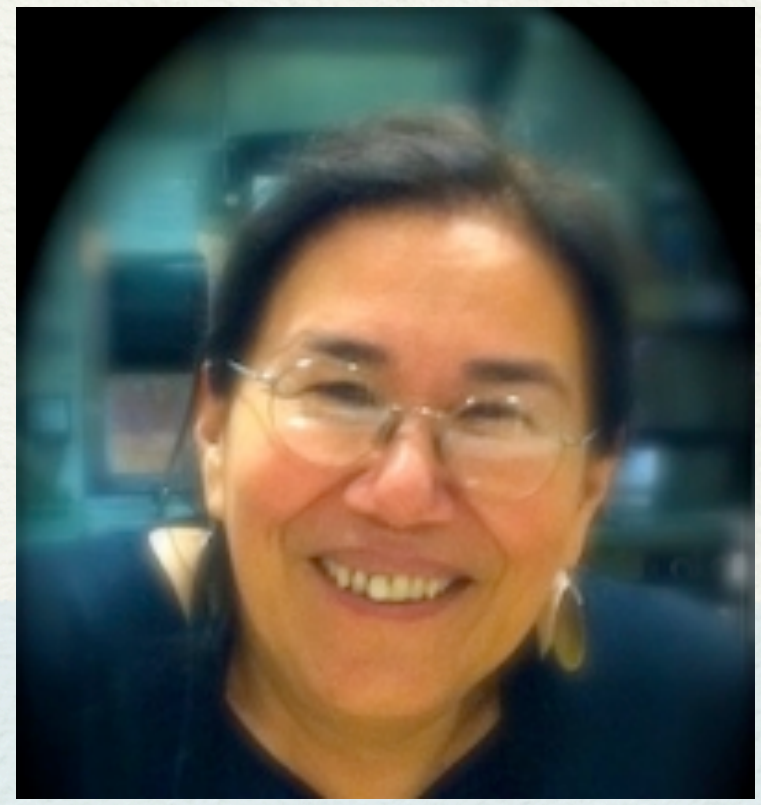

Registration: http://cgi.sfu.ca/ hccweb/cgibin/OnlineRegistration/site/event/detail.php?id=1007

Program: http://www.sfu.ca/fcat/research-centresinstitutes/cpcc/events.html

Three panels and a roundtable discussion will follow the keynote. Panelists will discuss their work and the ethical/political potentialities and dilemmas they encounter. Audience members are invited to participate in discussions. Presenters will include: Nadine Boulay, Jade Boyd, Susan Boyd, Henry Daniels, Pat Feindel, Adel Iskandar, Roy Miki, Nawal Musleh-Motut, Michelle Nahanee, Deanna Reder, Leslie Robertson and annie ross.

Sponsors: FCAT's Centre for Policy Studies on Culture\&Communities, the Department of Sociology and Anthropology, the Office of the Associate Vice-President, External Relations (SFU), Office for Aboriginal Peoples (SFU), Faculty of Graduate Studies (SFU), Institute for Humanities (SFU), Vancity Office of Community Engagement, Institute for Performance Studies (SFU), Centre for Social Justice (Kwantlen Polytechnic University), Centre for Imaginative Ethnography 